\title{
Albumin stimulates interleukin-8 expression in proximal tubular epithelial cells in vitro and in vivo
}

\author{
Sydney Tang, ${ }^{1}$ Joseph C.K. Leung, ${ }^{1}$ Katsushige Abe, ${ }^{3}$ Kwok Wah Chan, ${ }^{2}$ \\ Loretta Y.Y. Chan, ${ }^{1}$ Tak Mao Chan, ${ }^{1}$ Kar Neng Lai ${ }^{1}$ \\ ${ }^{1}$ Division of Nephrology, Department of Medicine, and \\ ${ }^{2}$ Department of Pathology, Queen Mary Hospital, The University of Hong Kong, Hong Kong, People's Republic of China \\ ${ }^{3}$ Division of Nephrology, Second Department of Internal Medicine, Nagasaki University School of Medicine, Nagasaki, Japan
}

\begin{abstract}
Renal tubulointerstitial injury is characterized by inflammatory cell infiltrate; however, the stimuli for leukocyte recruitment are not fully understood. IL-8 is a potent chemokine produced by proximal tubular epithelial cells (PTECs). Whether nephrotic proteins stimulate tubular IL-8 expression remains unknown. Acute exposure of human PTECs to albumin induced IL-8 gene and protein expression time- and dose-dependently. Apical albumin predominantly stimulated basolateral IL-8 secretion. Electrophoretic mobility shift assay demonstrated nuclear translocation of NF- $\mathrm{KB}$, and the $\mathrm{p} 65 / \mathrm{p} 50$ subunits were activated. NF- $\mathrm{KB}$ activation and IL-8 secretion were attenuated by the NF- $\mathrm{KB}$ inhibitors pyrrolidine dithiocarbamate and cell-permeable peptide. Albumin upregulated intracellular reactive oxygen species (ROS) generation, while exogenous $\mathrm{H}_{2} \mathrm{O}_{2}$ stimulated NF- $\kappa B$ translocation and IL-8 secretion. Albumin-induced ROS generation, NF- $\mathrm{KB}$ activation, and IL-8 secretion were endocytosis- and PKC-dependent as these downstream events were abrogated by the PI3K inhibitors LY294002 and wortmannin, and the PKC inhibitors GF109203X and staurosporin, respectively. In vivo, IL-8 mRNA expression was localized by in situ hybridization to the proximal tubules in nephrotic kidney tissues. The intensity of IL-8 immunostaining was higher in nephrotic than non-nephrotic subjects. In conclusion, albumin is a strong stimulus for tubular IL-8 expression, which occurs via $\mathrm{NF}-\mathrm{KB}-$ dependent pathways through PKC activation and ROS generation.
\end{abstract}

J. Clin. Invest. 111:515-527 (2003). doi:10.1172/JCI200316079.

\section{Introduction}

Tubulointerstitial damage followed by scarring and progressive loss of renal function is the final common pathologic pathway in many forms of chronic proteinuric renal diseases. The severity of tubulointerstitial injury, which correlates with the amount of proteinuria (1), is a major determinant of the degree and rate of progression of renal failure (2). The putative role of urinary proteins (taken to reflect the degree of protein trafficking through the glomerular capillary) in inducing tubulointerstitial changes is supported by clinical observations (3) as well as animal models of protein overload (4) and

Received for publication June 5, 2002, and accepted in revised form December 30, 2002.

Address correspondence to: K.N. Lai, Department of Medicine, University of Hong Kong, Queen Mary Hospital, 102 Pokfulam

Road, Hong Kong, People's Republic of China.

Phone: 852-2855-4251; Fax: 852-2816-2863;

E-mail: knlai@hkucc.hku.hk.

This work was presented in abstract form at the World Congress of Nephrology jointly organized by the American and

International Societies of Nephrology (ASN/ISN), San Francisco, California, USA, on October 14-17, 2001.

Conflict of interest: The authors have declared that no conflict of interest exists.

Nonstandard abbreviations used: proximal tubular epithelial cells (PTECs); pyrrolidine dithiocarbamate (PDTC);

electrophoretic mobility shift assay (EMSA); reactive oxygen

species (ROS); 5- (and 6-) chloromethyl-2', $7^{\prime}$-dichloro-

dihydrofluorescein diacetate $\left(\mathrm{CM}-\mathrm{H}_{2} \mathrm{DCFDA}\right)$; mean

fluorescence intensity (MFI); digoxigenin (DIG). experimental nephrotic syndrome $(5,6)$. The mechanisms through which urinary proteins induce tubulointerstitial damage, however, remain largely unknown.

Emerging evidence over the last decade indicates that interstitial lesions induced by proteinuria may be mediated through tubular epithelial cell activation (7). One constant feature of proteinuric nephritis is the concomitant presence of tubulointerstitial inflammation, which is characterized by the infiltration of the interstitial space by mononuclear leukocytes, notably $\mathrm{T}$ cells and macrophages, which appear to play a key role in the subsequent evolution of tubulointerstitial inflammation and fibrosis (8). The stimuli responsible for the initial recruitment of inflammatory cells into the interstitium are not fully understood, but chemokines secreted by tubular cells almost certainly play a pivotal role. For instance, MCP-1 and RANTES are two C-C chemokines that are upregulated by albumin in cultured proximal tubular cells $(9,10)$. Their known chemotactic activities for monocytes and $\mathrm{T}$ cells support the proinflammatory role of the proximal tubular cell in directing tubulointerstitial infiltrates in proteinuric renal disease.

IL-8 is a prototype chemokine of the C-X-C family that has potent chemotactic activity at nanomolar and picomolar concentrations for neutrophils and lymphocytes, respectively (11). Circumstantial evidence suggesting a role for IL-8 in renal interstitial inflammation comes from the following observations: (a) tubular epithelial cells are capable of synthesizing 
IL-8 (12); (b) IL-8 production by tubular epithelial cell is regulated by a variety of proinflammatory cytokines, most notably IL-1, TNF- $\alpha$, and IFN- $\gamma(12,13)$; and (c) urinary levels of IL-8 are increased in patients with various forms of glomerular diseases, such as IgA nephropathy, membrano-proliferative glomerulonephritis, and lupus nephritis $(14,15)$. On the other hand, whether the proteinuric state would also stimulate tubular production of IL-8 remains unknown.

In the present study, we present in vitro data to show that albumin superinduces tubular production of IL-8. The underlying intracellular signaling mechanisms are explored. We also attempt to localize the in vivo site of IL-8 production by performing in situ hybridization and immunohistochemistry studies on human nephrotic renal tissue. The functional consequences of abnormal protein trafficking through the glomerulus and the transcriptional regulation of tubular IL-8 synthesis are discussed.

\section{Methods}

Reagents. Medium, reagents for cell culture, Ab's for cell characterization, PI3K inhibitors (wortmannin and LY294002), PKC inhibitors (staurosporin and GF109203X), and general chemicals were purchased from Sigma-Aldrich Ltd. Co. (Paisley, United Kingdom). HSA was obtained from CSL Laboratory (CSL Limited, Parkville, Victoria, Australia). Other brands of HSA were obtained from Calbiochem-Novabiochem Corp. (San Diego, California, USA) and Sigma-Aldrich. The endotoxin level in all albumin preparations were $<10 \mathrm{EU} / \mathrm{ml}$, as determined using the QCL-1000 limulus amebocyte lysate kit (BioWhittaker Inc., Walkersville, Maryland, USA). Antibiotics, sera, agarose, and DNA size markers were obtained from Invitrogen Corporation (Carlsbad, California, USA). Reagents for cDNA synthesis were obtained from Life Technologies Inc. (Paisley, United Kingdom) and Promega Corp. (Madison, Wisconsin, USA), and those for PCR and cycle sequencing were from Perkin Elmer Life Sciences Inc. (Boston, Massachusetts, USA). The enzyme immunoassay kit for detection of IL-8 was purchased from Bender MedSystems (Vienna, Austria). Ab's for detection of DNA-bound NF- $\kappa B$ by flow cytometry and cell membrane-permeable inhibitory pep-

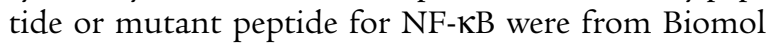
Research Laboratories (Plymouth Meeting, Pennsylvania, USA) and Dakopatts (Glostrup, Denmark). The fluorescence probe for intracellular reactive oxygen species detection was from Molecular Probes Inc. (Eugene, Oregon, USA). Reagents and Ab's for in situ hybridization were from Boehringer Mannheim GmbH (Mannheim, Germany). Anti-Tamm-Horsfall glycoprotein was from Chemicon International (Temecula, California, USA). All other Ab's were from DAKO A/S (Glostrup, Denmark). Cell culture. Human colorectal epithelial cell line (HT-29) and human lung type 2 epithelial cell line (A549) were obtained from American Type Culture Collection (Rockville, Maryland, USA). Human proximal tubular epithelial cells (PTECs) were isolated according to a method described previously (16). Briefly, renal cortical tissue was obtained from kidneys removed for circumscribed tumors. Histological examination of these kidney samples revealed no renal pathology. Cortical specimens were cut into small cubes and passed through a series of mesh sieves of diminishing pore size. PTECs were collected on the $53-\mu \mathrm{m}$ sieve and digested with collagenase $(750 \mathrm{U} / \mathrm{ml})$ at $37^{\circ} \mathrm{C}$ for $15 \mathrm{~min}$. Tubular cells were isolated by centrifugation and grown in a $1: 1$ mixture of DMEM and Ham's F12 medium supplemented with $10 \%$ FCS, hydrocortisone $(40 \mathrm{ng} / \mathrm{ml})$, L-glutamine $(2 \mathrm{mM})$, benzyl penicillin (100 IU/ml), and streptomycin $(100 \mu \mathrm{g} / \mathrm{ml})$. The cells were incubated at $37^{\circ} \mathrm{C}$ in $5 \% \mathrm{CO}_{2}$ and $95 \%$ air. They were characterized to be of proximal tubular origin by immunofluorescence and enzyme histochemistry: cells stained positively for cytokeratin, vimentin, and alkaline phosphatase, but negatively for Tamm-Horsfall glycoprotein, factor VIII-related antigen, and $\alpha$-smooth muscle actin. Scanning electron microscopy demonstrated the presence of numerous apical microvilli of a rudimentary brush border with reassembly of tight junctions. Experiments were performed with cells up to the third passage, because it has been shown that there are no phenotypic changes up to this passage number (17). In all experiments, there was a "growth-arrest" period of $48 \mathrm{~h}$ in serum-free medium prior to stimulation. Results were obtained from PTECs cultured from the kidneys of three different donors.

RNA extraction and cDNA synthesis. Total RNA was extracted from PTEC monolayers by a modification of the method by Chomczynski and Sacchi (18). Briefly, cells were lysed in a commercially available lysis buffer, which contained a mixture of phenol and guanidinium thiocyanate in a monophasic solution (RNA Isolator; Genosys Biotechnologies, Cambridge, United Kingdom). This was followed by chloroform extraction and isopropanol precipitation. RNA was quantified by absorbance at $260 \mathrm{~nm}$. Five micrograms total RNA were reverse transcribed to cDNA with Superscript II reverse transcriptase (Life Technologies Inc.) in a 20- $\mu \mathrm{l}$ reaction mixture containing 160 ng oligo-(dT) $)_{12-18}, 500$ $\mu \mathrm{M}$ of each dNTP, and $40 \mathrm{U}$ RNase inhibitor for $10 \mathrm{~min}$ at $37^{\circ} \mathrm{C}, 60 \mathrm{~min}$ at $42^{\circ} \mathrm{C}$, and $5 \mathrm{~min}$ at $99^{\circ} \mathrm{C}$. The cDNA was stored at $-20^{\circ} \mathrm{C}$ until further use.

Analysis of IL-8 gene expression. PTECs, A549, or HT-29 were grown to confluence in six-well cell culture plates (Falcon; Becton-Dickinson UK Ltd., Cowley, United Kingdom), growth arrested, and exposed to albumin $(1.25-20 \mathrm{mg} / \mathrm{ml})$ for defined time periods $(3-48 \mathrm{~h})$ at $37^{\circ} \mathrm{C}$. Total cellular RNA was then extracted and reverse transcribed to cDNA. PCR was carried out as described previously (19). The oligonucleotide sequences of cDNA primers for IL-8, designed from GenBank, were as follows: forward, ATG ACT TCC AAG CTG GCC GTG CT and reverse, TCT CAG CCC TCT TCA AAA ACT TCT, yielding an amplified product of $298 \mathrm{bp}$. PCR reactions were carried out in a DNA thermal cycler (MJ Research, Watertown, Massachusetts, USA), with 33 cycles of amplification at an annealing temperature of $55^{\circ} \mathrm{C}$. For quantification, 
human $\alpha$-actin primers were included in every reaction as an internal control. The primers, based on the known sequence of human $\alpha$-actin cDNA (20), were as follows: forward, GGA GCA ATG ATC TTG ATC TT, and reverse, TCC TGA GGT ACG GGT CCT TCC, yielding an amplified product of $204 \mathrm{bp}$. The PCR products were separated by $1.5 \% \mathrm{wt} / \mathrm{vol}$ agarose gels, stained with ethidium bromide (Sigma-Aldrich Co. Ltd.), and the gel image was captured and analyzed using the Gel Doc 1000 Densitometry System and Quantity One (Bio-Rad Laboratories Inc., Hercules, California, USA). The product yield was expressed as a ratio to $\alpha$-actin. The sequence of IL- 8 amplicon was verified by standard cycle sequencing technique (21).

Assay of IL-8 protein in culture supernatants and urine. PTECs, A549, or HT-29 were grown to confluence in sixwell cell culture plates, growth arrested, and exposed to albumin $(1.25-20 \mathrm{mg} / \mathrm{ml})$ for defined time periods (3-48 h) at $37^{\circ} \mathrm{C}$. For some experiments, PTECs were cultured for $24 \mathrm{~h}$ with HSA from other suppliers (Sigma-Aldrich Co. Ltd. or Calbiochem-Novabiochem), or with $10 \mathrm{mg} / \mathrm{ml}$ human transferrin, human IgG, trypsin-digested HSA (HSA digested with trypsin-conjugated agarose for $2 \mathrm{~h}$ ), or boiled HSA (as albumin started to precipitate at $75^{\circ} \mathrm{C}$ and beyond to assume a gelatinous state, an aggregation by intermolecular association of the protein molecules that prevented its direct application to the cell culture system, boiling of diluted HSA was performed to achieve thermal denaturation; ref 22). Supernatants were collected and stored at $-70^{\circ} \mathrm{C}$ until further use, while cell number was counted after trypsinization. Twenty-four-hour urine samples were collected from proteinuric subjects, and representative aliquots were stored at $-70^{\circ} \mathrm{C}$ until assay. Detection of the IL-8 level in culture supernatants and urine was carried out on a commercially available assay kit, according to the manufacturer's instructions (Bender MedSystems). The detection sensitivity and intra-assay coefficient of variation is $11 \mathrm{pg} / \mathrm{ml} \pm 3.8 \%$ for IL-8.

Examination of polarity of IL-8 secretion by PTECs. To examine the polarity of IL-8 secretion, second-passage PTECs were seeded into 12-well Transwell chambers (0.4- $\mu \mathrm{m}$ pore size, $10-\mathrm{mm}$ diameter; Corning Costar Corp., Cambridge, Massachusetts, USA) and maintained at confluence for 2 days before use. Different concentrations of albumin $(2.5-10 \mathrm{mg} / \mathrm{ml})$ were added either to the upper or lower chamber, which corresponded to the apical or basolateral side of the cells. respectively, while medium alone $(1.5 \mathrm{ml})$ was added to the other compartment. After 24 hours of incubation, supernatants in the upper and lower chambers were harvested separately and assayed for IL-8, while cell number was counted. All experiments were performed in triplicate.

Endocytosis of FITC-HSA. PTECs were grown to confluence in 24-well cell culture plates, growth arrested, and exposed to fluorescein-labeled HSA (FITC-HSA, $1.25-20 \mathrm{mg} / \mathrm{ml}$ ) for $30 \mathrm{~min}$ or $5 \mathrm{mg} / \mathrm{ml}$ FITC-HSA for $0-4$ hours at $37^{\circ} \mathrm{C}$. The cells were then harvested, fixed with $1 \%$ paraformaldehyde, examined by fluorescence microscopy, and counted with a fluorescence microplate reader (Tecan Austria GmbH, Salzburg, Austria). Experiments were performed in triplicate.

Measurement of DNA-bound NF- $\kappa B$ by flow cytometry. DNA-bound NF- $\mathrm{BB}$ was determined by flow cytometry, according to a method described previously (23). Briefly, PTECs were cultured to confluence in six-well plates and were growth arrested for $24 \mathrm{~h}$ in serum-free culture medium. The cells were then incubated with or without albumin for $30 \mathrm{~min}$ and were harvested by trypsinization. Cells were washed with wash buffer (PBS with $2 \%$ FBS) and lysed with lysis buffer (10 mM PIPES, 0.1 M $\mathrm{NaCl}, 2 \mathrm{mM} \mathrm{MgCl}_{2}, 0.1 \%$ Triton X-100, $\mathrm{pH}$ 6.8). The isolated nuclei preparations were stained with rabbit polyclonal Ab (Rel A or NF-אB1; Biomol Research Laboratories) or nonimmune rabbit immunoglobulins at a final concentration of $10 \mu \mathrm{g} / \mathrm{ml}$ for $30 \mathrm{~min}$. After further washing, $100 \mu \mathrm{l}$ of FITC-conjugated swine anti-rabbit immunoglobulins (Dakopatts) diluted 1:20 in permeabilization buffer were added and incubated for a further $30 \mathrm{~min}$. The nuclei were washed and analyzed for DNA-bound NF- $\mathrm{BB}$ by flow cytometer (Coulter EPICS XL analyzer; Coulter Electronics Ltd., Miami, Florida, USA). Results were analyzed using Flowjo software (Tree Star Software, San Carlos, California, USA) and were expressed as mean fluorescence intensity.

Effect of NF- $\kappa B$ inbibitors on albumin-induced $I L-8$ synthesis. To study a possible relationship between albumin-induced IL-8 production and the transcriptional factor NF- $\kappa$ B, PTECs were plated on six-well tissue culture plates and, when confluent, treated with the $\mathrm{NF}-\kappa \mathrm{B}$ inhibitor pyrrolidine dithiocarbamate(PDTC; 5 or $25 \mu \mathrm{M}$; Sigma-Aldrich Co. Ltd.) (24) or $100 \mu \mathrm{g} / \mathrm{ml}$ cell membrane-permeable peptides (25) (SN50M or SN50; Biomol Research Laboratories) for $1 \mathrm{~h}$ before and during 6-hour incubation with $10 \mathrm{mg} / \mathrm{ml}$ albumin. (The sequence of SN50 was AAVALLPAVLLALLAPVQRKRQKLMP, which can inhibit the translocation of the active NF- $\mathrm{KB}$ complex into the nucleus, and the sequence of the control peptide SN50M was AAVALLPAVLLALLAPVQRNGQKLMP. The nuclear localization sequence of NF- $\mathrm{KB}$ was underlined, and the mutant residues in SN50M were in italics.) At the end of the incubation, IL-8 was measured in supernatants.

Electrophoretic mobility shift assay. A standard electrophoretic mobility shift assay (EMSA) was used to further examine the role of the transcriptional factor NF- $\kappa B$ in albumin-induced IL-8 production. PTECs were plated on a T25 tissue-culture flask and, upon confluence, treated with albumin (5 or $10 \mathrm{mg} / \mathrm{ml}$ ) alone, or $25 \mu \mathrm{M}$ PDTC (Sigma-Aldrich Co. Ltd.), or $100 \mu \mathrm{g} / \mathrm{ml}$ cell membranepermeable peptides (SN50M or SN50) for $30 \mathrm{~min}$ before and during 1-hour incubation with albumin $(10 \mathrm{mg} / \mathrm{ml})$. At the end of the incubation, nuclear extract was prepared using NE-PER nuclear extraction reagent (Pierce Chemical Co., Rockford, Illinois, USA) and stored at $-70^{\circ} \mathrm{C}$ until the assay was performed. Gel-shift oligonucleotide for NF-kB (AGTT-GAGGGGACTTTCCCAGGC; the core sequence was underlined) was biotinylated using 


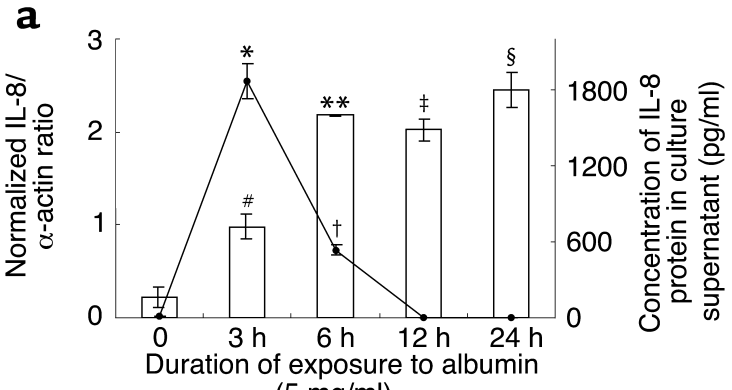

$(5 \mathrm{mg} / \mathrm{ml})$

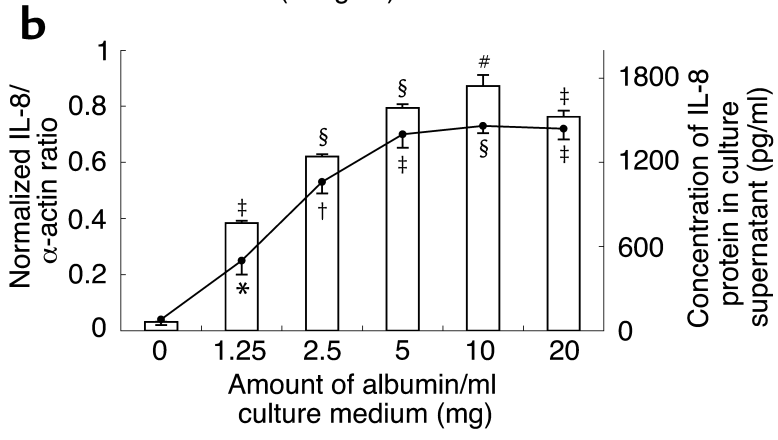

biotin 3' end-labeling kit (Pierce Chemical Co.), and the EMSA was carried out with the LightShift chemiluminescent EMSA kit (Pierce Chemical Co.) according to the manufacturer's instruction.

Measurement of intracellular reactive oxygen species. The intracellular formation of reactive oxygen species (ROS) was detected by the fluorescence probe 5- (and 6-) chloromethyl-2', $7^{\prime}$-dichlorodihydrofluorescein diacetate (CM- $\mathrm{H}_{2}$ DCFDA; Molecular Probes Inc.). PTECs $\left(10^{6} / \mathrm{ml}\right)$ were cultured in the presence of different doses of HSA $(1.25-20 \mathrm{mg} / \mathrm{ml})$ for $30 \mathrm{~min}$ and then loaded with 0.1 $\mu \mathrm{g} / \mathrm{ml} \mathrm{CM}-\mathrm{H}_{2}$ DCFDA. The cells were placed on ice. ROS production, expressed as DCF mean fluorescence intensity (MFI), was immediately measured by flow cytometry using a Coulter EPICS XL analyzer (Coulter Electronics Ltd.). Results were expressed as percentage of MFI of control cells incubated with culture medium alone.

Effect of exogenous $\mathrm{H}_{2} \mathrm{O}_{2}$ on NF- $\kappa B$ translocation and IL-8 secretion in PTECs. Confluent PTECs grown on six-well tissue-culture plates were treated with $\mathrm{H}_{2} \mathrm{O}_{2}(200 \mu \mathrm{M})$ for $1 \mathrm{~h}$ for determination of NF- $\mathrm{KB}$ activation by EMSA or with $\mathrm{H}_{2} \mathrm{O}_{2}(50,100,200$, or $400 \mu \mathrm{M})$ for $24 \mathrm{~h}$ for assay of IL-8 protein in culture supernatants by ELISA. Effect of PI3K inhibitors or PKC inbibitors on albumin-induced ROS generation, NF- $K B$ translocation, and IL-8 secretion.

\section{Figure 2}

Effect of albumin from different suppliers, heat or protease pretreatment, and nonalbumin serum proteins. Confluent, growtharrested PTECs were cultured for $24 \mathrm{~h}$ with $10 \mathrm{mg} / \mathrm{ml}$ of HSA from different suppliers (shown in parentheses), human transferrin, human $\operatorname{lgG}$, boiled HSA (HSA boiled for $10 \mathrm{~min}$ ), or trypsin-digested HSA (HSA digested with trypsin-conjugated agarose for $2 \mathrm{~h}$ ). IL-8 protein secretion was measured in cell culture supernatants by ELISA. Results are means \pm SD of triplicate experiments. ${ }^{*} P<0.0001$, $\dagger P=0.001$ versus cells incubated in serum-free medium alone; ${ }^{\#} P<0.0001$ versus cells treated with HSA 1, HSA 2, or HSA 3.

\section{Figure 1}

Effect of acute exposure to albumin on IL-8 expression by PTECs. (a) Time response. Confluent, growth-arrested cells were cultured in serum-free medium or medium containing $5 \mathrm{mg} / \mathrm{ml} \mathrm{HSA}$ for 3-24 h. IL-8 gene expression (line) was quantified by RT-PCR, while protein secretion in culture supernatants (bars) was assayed by ELISA. Results are means \pm SD obtained from duplicate experiments of three different kidney preparations. ${ }^{*} P<0.0001,+P=0.008,{ }^{\#} P=0.027$, ${ }^{*} P=0.002, \ddagger P=0.004, \S P=0.01$ compared with growth-arrested cells incubated in serum-free medium alone for equivalent duration. (b) Dose response. Confluent, growth-arrested cells were cultured in serum-free medium or medium containing escalating doses of HSA for 3 h. IL-8 gene expression (line) and protein secretion (bars) were measured as stated above. Results are means \pm SD obtained from duplicate experiments of three different kidney preparations. ${ }^{*} P=0.011, \dagger P=0.004, \ddagger P=0.001, \S P<0.0001,{ }^{\#} P=0.002$ compared with growth-arrested cells incubated in serum-free medium alone.

Confluent PTECs grown on six-well tissue-culture plates were treated with the PI3K inhibitors, wortmannin (500 $\mathrm{nM})$ or LY294002 $(100 \mu \mathrm{M})$, or the PKC inhibitors, staurosporin $(100 \mathrm{nM})$ or GF109203X $(5 \mu \mathrm{M}), 1 \mathrm{~h}$ before and during incubation with albumin $(10 \mathrm{mg} / \mathrm{ml})$. At the end of the incubation period ( $30 \mathrm{~min}$ for ROS assay, $1 \mathrm{~h}$ for NF-KB EMSA, and $24 \mathrm{~h}$ for supernatant IL-8 protein assay), intracellular ROS generation, NF- $\mathrm{KB}$ translocation, and IL-8 secretion were determined by flow cytometry, EMSA, and ELISA, respectively, as described above.

Immunohistochemical localization of IL-8 production on buman nephrotic kidneys and cultured PTECs. To localize the site of IL-8 production in vivo, immunohistochemical staining was performed on renal biopsy tissues obtained from nephrotic subjects with nonproliferative glomerulopathies (minimal change nephrotic syndrome, diabetic and hypertensive nephrosclerosis), and from patients with no or minimal proteinuria and histology of no or minor abnormality as control.

Paraffin-embedded human kidney tissues were sectioned at a thickness of $4 \mu \mathrm{m}$, and the sections were deparaffinized with xylene and then rehydrated through a descending gradient of ethanol. IL-8 expression on paraffin sections was determined by immunohistochemical staining using monoclonal anti-human IL-8 Ab (Santa Cruz Biotechnology Inc., Santa Cruz, California, USA). Briefly, the slides were incubated

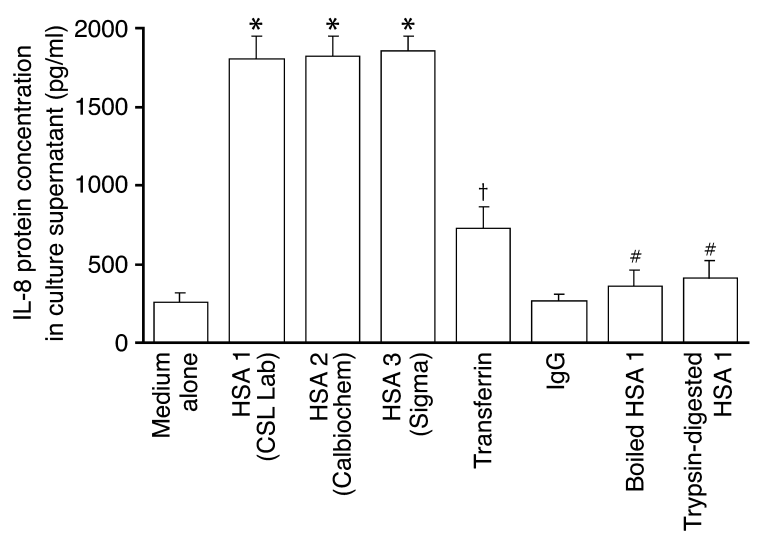


a

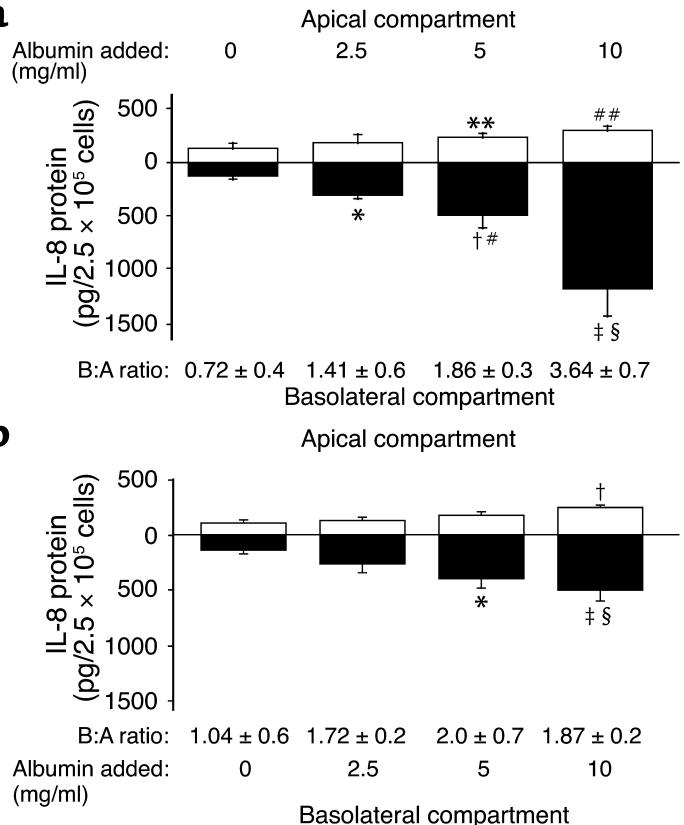

with $0.5 \% \mathrm{H}_{2} \mathrm{O}_{2}$ for removal of endogenous peroxidase activity. Nonspecific binding was blocked by incubation of the slides for $30 \mathrm{~min}$ with blocking buffer $(5 \%$ normal goat serum and $3 \% \mathrm{BSA}$ in PBS). The sections were then incubated with anti-IL-8 $(10 \mu \mathrm{g} / \mathrm{ml}) \mathrm{Ab}$ 's overnight. The bound murine anti-IL-8 Ab's were visualized using the DAKO Envision Plus System (DAKO Corp., Carpinteria, California, USA). For some sections, infiltrating leukocytes were demonstrated by staining with monoclonal anti-CD44 (DAKO Corp.). To confirm the specificity of anti-IL- 8 used in the present study, cultured PTECs grown in chamber slides with or without albumin $(10 \mathrm{mg} / \mathrm{ml})$ were stained with

\section{Figure 3}

Polarized production of IL- 8 by PTECs. Cells were grown to confluence on Transwell chambers and growth arrested. Serum-free medium alone (control) or supplemented with different concentrations of HSA was added to the apical (a) or basolateral (b) chamber, while medium alone was added to the other compartment. After overnight incubation, apical medium (white bars) and basolateral medium (black bars) were harvested for assay of IL-8 protein by ELISA. Numbers below each pair of bars represent the ratio of basolateral/apical IL-8 secretion. Results are means \pm SD obtained from triplicate experiments of one kidney preparation. (a) ${ }^{*} P=0.002, \dagger P=0.006, \neq P=0.018$ versus control basolateral compartment; ${ }^{*} P=0.038,{ }^{\# \#} P=0.009$ versus control apical compartment; ${ }^{\#} P=0.037, \S P=0.005$ versus corresponding apical compartments. (b) $* P=0.024, \neq P=0.02$ versus control basolateral compartment; ${ }^{\dagger} P=0.003$ versus control apical compartment; $\S P=0.02$ versus corresponding apical compartment.

anti-IL-8 as described above. Ab preabsorbed with IL-8-immunizing peptides was used as control.

A renal histopathologist without prior knowledge of clinical or laboratory data examined the tissues histologically and evaluated the expression of IL-8 staining using an arbitrary $0-3+$ scale (absent or minimal, mild, moderate, and marked). For glomerular staining, the scoring criteria were as follows: minimal if $<5 \%$ glomerular cells were positive; mild if $5 \%$ to $<25 \%$ cells were positive; moderate if $25 \%$ to $<50 \%$ cells were positive; and marked if $50 \%$ or more cells were positive. For tubular staining, the grading criteria were as follows: minimal if $<10 \%$ cortical tubular cells were positive; mild if $10 \%$ to $<40 \%$ cells were positive; moderate if $40 \%$ to $<80 \%$ cells were positive; and marked if $80 \%$ or more cells were positive.

Oligonucleotides and labeling. A 42-mer sequence of mRNA was selected for human IL-8. Antisense oligonucleotides for human IL-8 corresponded to bases 2435-2476 of human IL-8 (26). The selected sequence was significantly different from other known sequences
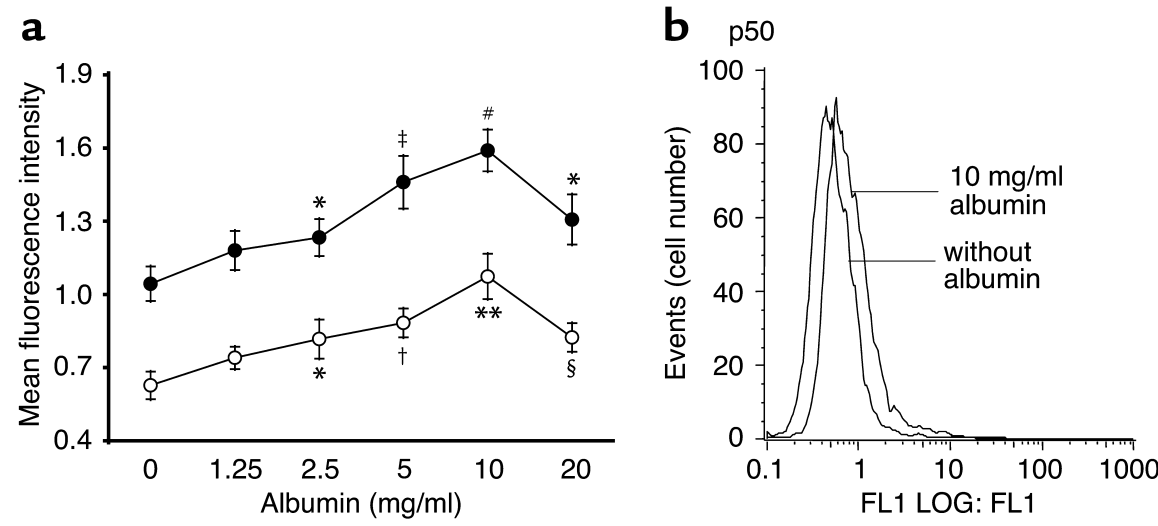

Fluorescence intensity

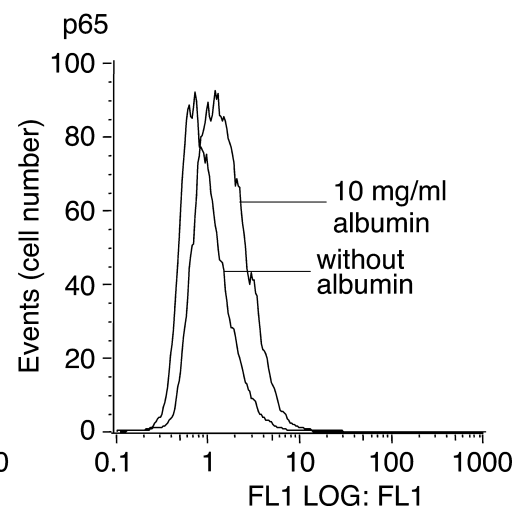

Fluorescence intensity

Figure 4

FACS analysis of nuclear expression of NF- $\mathrm{KB} /$ Rel proteins on PTECs. (a) Confluent PTECs were incubated in serum-free medium or medium containing escalating doses of albumin as shown. After $30 \mathrm{~min}$, cells were lysed, and the cell nuclei were isolated and stained with rabbit polyclonal Ab against p65 (Rel A, filled circles), or p50 (NF-KB1, open circles), or nonimmune rabbit immunoglobulins for analysis of DNA-bound $\mathrm{NF}-\mathrm{KB} /$ Rel proteins by flow cytometry. Results, expressed as MFI $\pm \mathrm{SD}$, are obtained from triplicate experiments. ${ }^{*} P<0.05,{ }^{\dagger} P=0.006$, $\ddagger P=0.005,{ }^{*} P=0.002,{ }^{\#} P=0.001, \S P=0.01$ versus cells exposed to serum-free medium alone. (b) Representative flow-cytometry histograms of unstimulated and albumin-stimulated cells labeled with anti-p65 or anti-p50 subunits and FITC-conjugated secondary Ab's. 


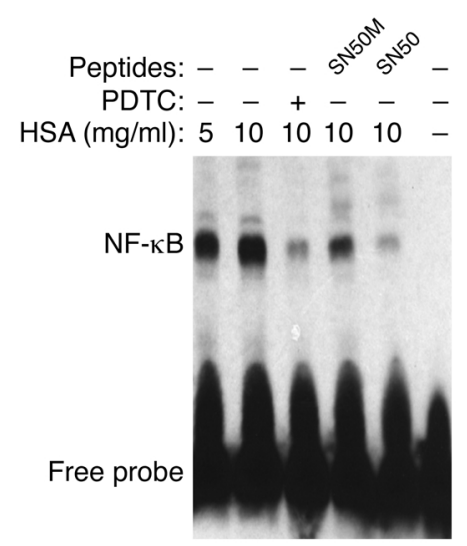

\section{Figure 5}

Role of NF- $\kappa B$ by EMSA. EMSA was performed with nuclear extracts of PTECs treated for $1 \mathrm{~h}$ with medium alone (control), HSA ( 5 or 10 $\mathrm{mg} / \mathrm{ml})$, PDTC ( $25 \mu \mathrm{M}$, added $30 \mathrm{~min}$ before the addition of HSA), SN50 or its mutant peptide SN50M $(100 \mu \mathrm{g} / \mathrm{ml}$, added $30 \mathrm{~min}$ before the addition of HSA). The results shown are representative of three independent experiments.

deposited in the latest release of the gene bank data (GenBank, Release 128, March 2002; http://www.ncbi. nlm.nih.gov/Genbank/). The oligonucleotide was synthesized on an automatic DNA synthesizer (391, PCRMATE EP; Applied Biosystems Inc., Foster City, California, USA) and was labeled using a digoxigenin (DIG) oligonucleotide tailing kit according to the current protocol (1417 231; Boehringer Mannheim GmbH, Mannheim, Germany).

Tissue localization of IL-8 gene expression by in situ bybridization. Nonradioactive in situ hybridization was performed according to a modified method developed in our laboratory (27). In brief, the specimens were cut to a thickness of $4 \mu \mathrm{m}$ and placed on glass slides coated with 3-aminopropyltriethoxysilane (A3684; Sigma-Aldrich, St. Louis, Missouri, USA). The sections were fixed with 4\% paraformaldehyde in PBS and then deproteinized using $\mathrm{HCl}$ and proteinase K (P-4914; Sigma-Aldrich). After prehybridization, the sections were hybridized with DIG-labeled oligonucleotide probe in prehybridization buffer ( $4 \times$ SSC, $0.5 \mathrm{M}$ sodium phosphate, $2.5 \times$ Denhalts solution, salmon testis DNA [D7656; Sigma-Aldrich], and transfer RNA [R5636; Sigma Aldrich]) at $40^{\circ} \mathrm{C}$ for $16 \mathrm{~h}$. After washing with $0.075 \%$ BRI (430 AG-6; SigmaAldrich) in $2 \times$ SSC twice for $20 \mathrm{~min}$ each and $0.5 \times$ SSC twice for $20 \mathrm{~min}$ each, at room temperature, sections were stained immunohistochemically to visualize the hybridized DIG-labeled probe using mouse monoclonal anti-DIG Ab (1333 062; Boehringer Mannheim $\mathrm{GmbH}$ ), HRP-conjugated rabbit anti-mouse Ab (DAKO P260; Dakopatts), and HRP-conjugated swine anti-rabbit Ab (DAKO P399; Dakopatts), successively. Color was developed by reaction with $\mathrm{H}_{2} \mathrm{O}_{2}$ and diaminobenzidine tetrahydrochloride. Finally, sections were counterstained with methyl green and mounted. Cells clearly stained in the cytoplasm or stained with a perinuclear pattern were identified as IL-8 mRNA-positive cells. On the other hand, cells with nuclei stained with methyl green alone were considered negative for IL-8 mRNA. To evaluate the specificity of the signals for IL- 8 mRNA, we performed three control experiments including pretreatment of RNase, a study with a sense probe, and a competitive study, as described previously $(28,29)$.

Statistical analysis. All data were expressed as means \pm SD, unless otherwise specified. Statistical analysis was performed using SPSS statistical software (Statistical Package for the Social Sciences Inc., Chicago, Illinois, USA). Intergroup differences for continuous variables were assessed by one-way ANOVA. Post hoc multiple comparisons using Tukey's Honestly Significant Difference test were used to determine the significance of differences between groups. Comparison of the score for the staining intensity by immunohistochemistry between groups was done using the Mann-Whitney $U$ test. Linear regression analysis was performed to determine the correlation between the staining score and age, serum creatinine, or proteinuria in the nephrotic group of subjects. Categorical data were compared by the Fisher exact test or the $X^{2}$ test, as appropriate. A $P$ value of less than 0.05 was considered statistically significant.

\section{Results}

Expression of IL-8 gene in PTECs. At the quiescent state, IL-8 gene expression in PTECs was barely detectable by RT-PCR. Acute exposure to HSA (CSL Laboratory) induced IL-8 gene expression in PTECs significantly. Maximal expression occurred at $3 \mathrm{~h}$ and then fell progressively to undetectable levels at $12 \mathrm{~h}$ and thereafter. IL-8 protein secretion also followed a timedependent manner and did not reach a maximum before $6 \mathrm{~h}$, due to the time required for the mRNA to be translated (Figure 1a). This was confirmed by additional assay experiments in which culture supernatants of PTEC exposed to albumin were removed at each

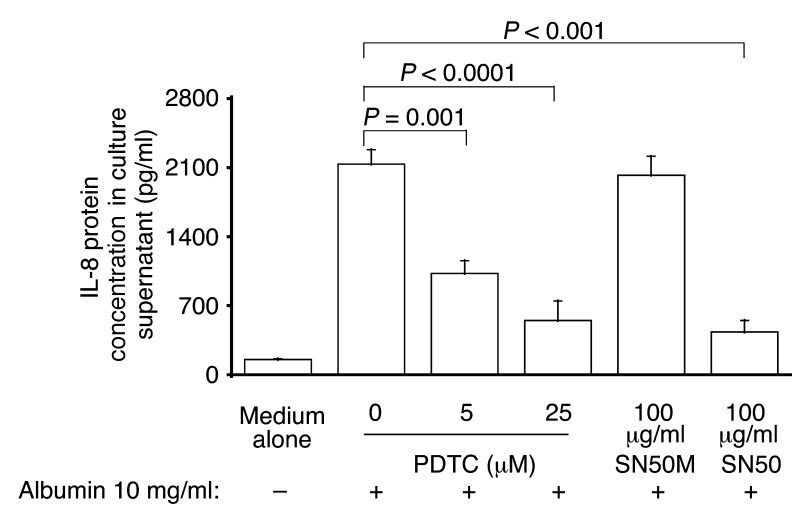

\section{Figure 6}

Effect of NF-KB inhibition on albumin-induced IL-8 synthesis. Confluent PTECs were treated for $6 \mathrm{~h}$ with medium alone, HSA (10 $\mathrm{mg} / \mathrm{ml}$ ), PDTC ( 5 or $25 \mu \mathrm{M}$, added $1 \mathrm{~h}$ before the addition of HSA), SN50, or its mutant peptide SN50M $(100 \mu \mathrm{g} / \mathrm{ml}$, added $1 \mathrm{~h}$ before the addition of HSA). At the end of incubation, IL-8 was measured in supernatants by ELISA, while cell number was counted. Results are means \pm SD of triplicate experiments of three kidney preparations. 


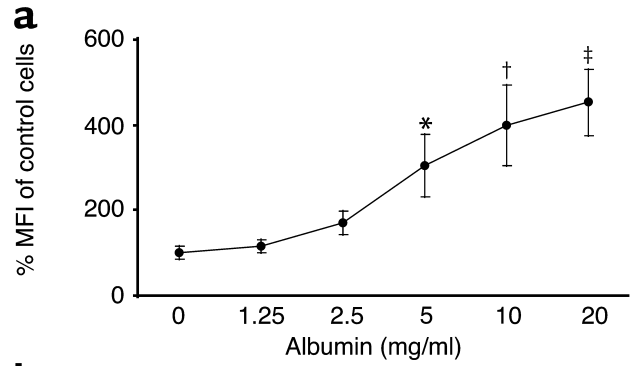

b

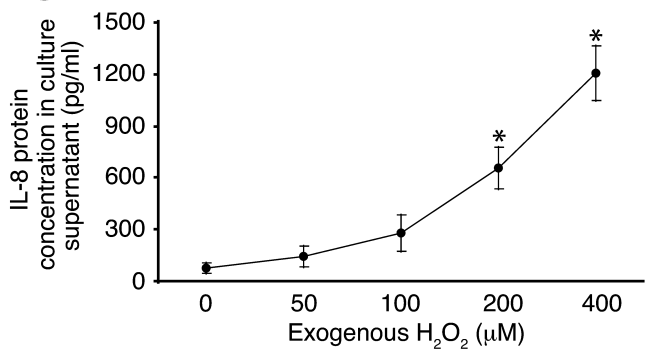

Figure 7

Role of ROS. (a) ROS induction by albumin. PTECs were exposed to HSA $(1.25-20 \mathrm{mg} / \mathrm{ml})$ for $30 \mathrm{~min}$. Intracellular ROS formation was detected by the fluorescence probe, $\mathrm{CM}-\mathrm{H}_{2}$ DCFDA, measured by flow cytometry, and expressed as percentage of MFI of control cells incubated with culture medium alone. Results are means \pm SD of triplicate experiments. ${ }^{*} P=0.013, \dagger P=0.001, \ddagger P<0.0001$ versus medium control. (b) Effect of exogenous $\mathrm{H}_{2} \mathrm{O}_{2}$. PTECs were exposed to $\mathrm{H}_{2} \mathrm{O}_{2}(50$, 100,200 , or $400 \mu \mathrm{M}$ ) for $24 \mathrm{~h}$. IL-8 protein secretion in culture supernatants was assayed by ELISA. Results are means \pm SD of triplicate experiments. ${ }^{*} P<0.0001$ versus medium control.

time point and replaced with fresh medium, and the IL-8 content in the replenished medium was then determined (data not shown).

IL-8 gene expression and protein secretion in PTECs was upregulated by albumin in a dose-dependent pattern, with significant induction after a 3-hour incubation with as little as $1.25 \mathrm{mg} / \mathrm{ml}$ albumin and beyond (Figure 1b). There was no significant change in the number of viable cells after exposure to albumin.

The effect of HSA on IL-8 secretion by PTECs was independent of the supplier of the albumin used, but was abolished by boiling (Figure 2). Trypsin digestion of albumin effectively degraded the protein into small peptides, as demonstrated by SDS-PAGE (data not shown). Such treatment significantly abrogated IL-8 induction in PTECs, as compared with neat albumin (Figure 2). Because transferrin and $\operatorname{IgG}$ are the main constituents of nephrotic urine apart from albumin, their effects were also tested. Transferrin, but not IgG, was capable of inducing IL-8 synthesis in PTECs, although to a lesser degree compared with albumin (Figure 2). In addition to PTECs, albumin also upregulated IL-8 mRNA expression and protein production in HT-29 (colorectal epithelial cell line) and A549 (lung type 2 epithelial cell line) cell lines in a dose-dependent fashion (data not shown).

Directional secretion of $I L-8$ protein in PTECs. Directional secretion of IL-8 is shown in Figure 3. Quiescent PTECs grown on permeable cell culture inserts secreted minute amounts of IL-8 equally into both apical and basolateral media. Apical exposure of PTECs to albumin led to dose-dependent increases in IL-8 secretion in both directions, with basolateral secretion predominating. Overnight incubation with $10 \mathrm{mg} / \mathrm{ml}$ albumin apically increased basolateral secretion of IL-8 by 10.8 -fold ( $P=0.018$ ), while apical secretion surged by 2.1 -fold $(P=0.009)$. The rise in basolateral secretion was significantly more robust than the apical increase $(P=0.005$ at $10 \mathrm{mg} / \mathrm{ml}$ albumin), altering the basolateral/apical ratio of IL-8 secretion from $0.72 \pm 0.4$ to $3.64 \pm 0.7$.

Basolaterally applied albumin also upregulated IL-8 secretion in PTECs, but to a much lesser extent (particularly with respect to basolateral IL-8 secretion), than apically applied albumin (Figure 3b).

Activation of NF- $\kappa B$ by buman serum albumin. To investigate whether the induction of IL-8 in PTECs by albumin was mediated by the transcription factor NF- $\kappa B$, cells incubated with or without albumin for $30 \mathrm{~min}$ were lysed for isolation of cell nuclei, which were stained with anti-p65 (Rel A) or anti-p50 (NF-kB1) subunits and then subjected to FACS analysis. In doseresponse studies, as little as $2.5 \mathrm{mg} / \mathrm{ml} \mathrm{HSA}$ activated NF- $\kappa B$ expression, with maximal activation occurring at $10 \mathrm{mg} / \mathrm{ml}$ (Figure 4). Both the p50 and p65 subunits, which are important in inflammatory responses, were activated to a similar degree. The translocation of NF- $\kappa B$ into the cell nucleus of PTECs after exposure to HSA was also demonstrated by EMSA (Figure 5).

Inbibition of $N F-\kappa B$. To confirm that NF- $\kappa B$ activation mediates IL-8 synthesis in PTECs, cells were treated with the NF-кB inhibitor, PDTC, or with the

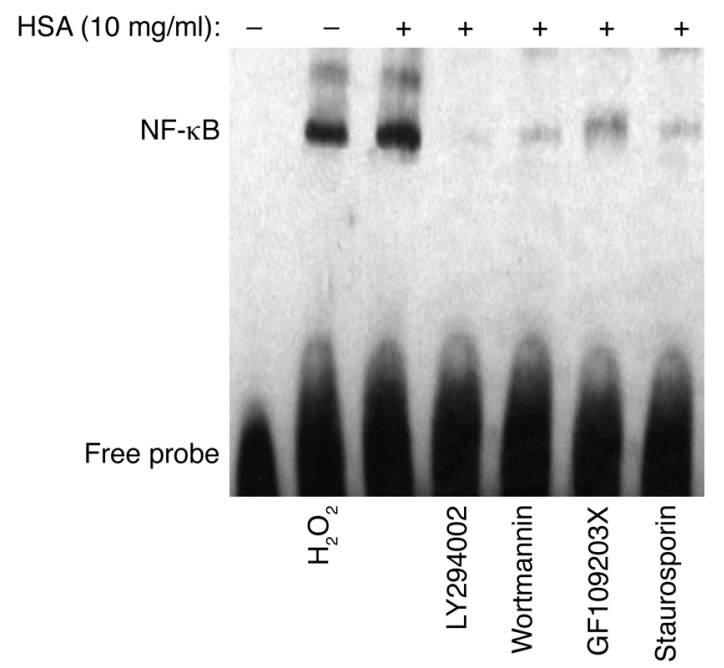

\section{Figure 8}

Effect of exogenous $\mathrm{H}_{2} \mathrm{O}_{2}$, or albumin with PI3K or PKC inhibitors on NF- $\kappa B$ activation in PTECs. EMSA was performed with nuclear extracts of PTECs treated for $1 \mathrm{~h}$ with medium alone (control), $\mathrm{H}_{2} \mathrm{O}_{2}(200 \mu \mathrm{M})$, HSA $(10 \mathrm{mg} / \mathrm{ml})$, LY294002 (100 $\mu \mathrm{M}$, added $1 \mathrm{~h}$ before the addition of HSA), wortmannin ( $500 \mathrm{nM}$, added $1 \mathrm{~h}$ before the addition of HSA), GF109203X ( $5 \mu \mathrm{M}$, added $1 \mathrm{~h}$ before the addition of HSA), or staurosporin (100 $\mathrm{nM}$, added $1 \mathrm{~h}$ before the addition of HSA). The results shown are representative of three independent experiments. 
a

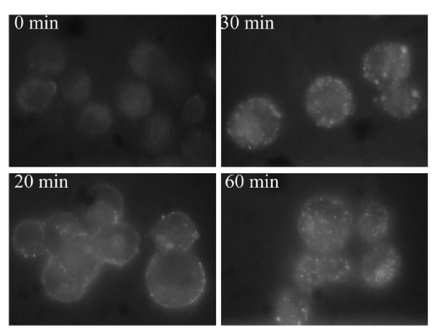

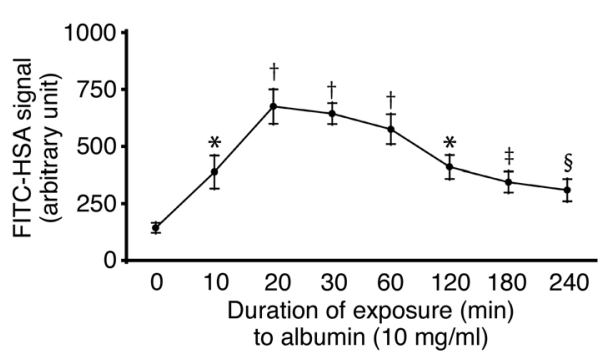

b

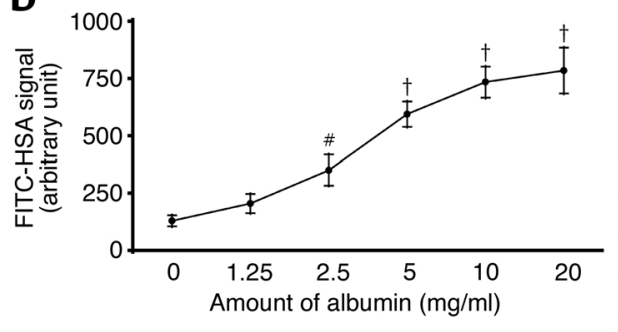

Figure 9

Endocytosis of albumin by PTECs. (a) Time response. Left panel: growth-arrested PTECs were exposed to fluorescein-labeled HSA (5 mg/ml) for $0-60 \mathrm{~min}$ at $37^{\circ} \mathrm{C}$. Cells were then fixed with $1 \%$ paraformaldehyde and examined by fluorescence microscopy. $\times 1,000$. Right panel: the fluorescence signals of cells incubated with FITC-HSA $(5 \mathrm{mg} / \mathrm{ml})$ for up to $4 \mathrm{~h}$ were counted using a fluorescence microplate reader. Results are means \pm SD of triplicate experiments. (b) Dose response. The fluorescence intensity of growth-arrested PTECs exposed to FITC-HSA $(1.25-20 \mathrm{mg} / \mathrm{ml})$ for $30 \mathrm{~min}$ was shown. Results are means $\pm \mathrm{SD}$ of triplicate experiments. ${ }^{*} P=0.001,{ }^{\dagger} P<0.0001, \neq P=0.008, \S P=0.036$, $\# P=0.012$ versus control cells exposed to FITC-HSA at time zero (a) or to buffer alone (b).

cell membrane-permeable peptide, SN50, which inhibits the translocation of the active NF- $\mathrm{KB}$ complex into the nucleus, for $1 \mathrm{~h}$ before and during incubation with HSA. As depicted in Figure 6, treatment with PDTC attenuated IL-8 secretion after exposure to albumin in a dose-dependent fashion. Treatment with SN50, but not its control peptide with mutant residues (SN50M), also abrogated IL-8 secretion.

In EMSA studies, both PDTC and SN50, but not the mutant peptide SN50M, blocked the nuclear translocation of NF-kB. Cells exposed to medium alone were used as control (Figure 5). In addition, cells treated with PDTC or peptides (SN50 or SN50M) alone or unlabeled $\kappa B$ oligonucleotide also demonstrated no shifting of the NF- $\mathrm{KB}$ complex by EMSA (electrophoretic gel not shown).

Role of ROS. The ability of PDTC, an antioxidant, to block albumin-induced NF-KB activation and IL-8 synthesis, suggested a role of ROS in the intracellular signaling of albumin. This was investigated by detecting intracellular ROS formation with the fluorescence probe,

\section{Figure 10}

Effect of PI3K and PKC inhibition on albumin-induced intracellular ROS generation and IL-8 secretion in PTECs. (a) ROS generation. PTECs were exposed for 30 min to medium alone (control), HSA (10 $\mathrm{mg} / \mathrm{ml}), \mathrm{LY} 294002(100 \mu \mathrm{M}$, added $1 \mathrm{~h}$ before the addition of HSA), wortmannin ( $500 \mathrm{nM}$, added $1 \mathrm{~h}$ before the addition of HSA), GF109203X ( $5 \mu \mathrm{M}$, added $1 \mathrm{~h}$ before the addition of HSA), or staurosporin (100 $\mathrm{nM}$, added $1 \mathrm{~h}$ before the addition of HSA). Intracellular ROS formation was detected by flow cytometry and expressed as percentage of MFI of control cells incubated with culture medium alone. Results are means \pm SD of triplicate experiments. ${ }^{*} P<0.0001$ versus medium control, ${ }^{\dagger} P=0.001$ versus cells treated with HSA alone. (b) IL-8 protein secretion. PTECs were treated for $24 \mathrm{~h}$ with medium alone (control), HSA $(10 \mathrm{mg} / \mathrm{ml}), \mathrm{LY} 294002(100 \mu \mathrm{M}$, added $1 \mathrm{~h}$ before the addition of HSA), wortmannin ( $500 \mathrm{nM}$, added $1 \mathrm{~h}$ before the addition of HSA), GF109203X ( $5 \mu \mathrm{M}$, added $1 \mathrm{~h}$ before the addition of HSA), or staurosporin ( $100 \mathrm{nM}$, added $1 \mathrm{~h}$ before the addition of HSA). At the end of incubation, IL-8 level was measured in supernatants using ELISA, while cell number was counted. Results are means \pm SD of triplicate experiments. ${ }^{*} P<0.0001$ versus medium control, ${ }^{\dagger} P<0.0001$ versus cells treated with HSA alone.
CM- $\mathrm{H}_{2} \mathrm{DCFDA}$. The magnitude of intracellular ROS formation was measured by flow cytometry and expressed as MFI. Upon exposure to HSA at $5 \mathrm{mg} / \mathrm{ml}$ and beyond for $30 \mathrm{~min}$, there was dose-dependent upregulation of intracellular ROS generation in PTECs (Figure 7a).

To demonstrate a direct role of ROS on the activation of NF- $\mathrm{KB}$, we exposed PTECs to exogenous $\mathrm{H}_{2} \mathrm{O}_{2}(200$ $\mu \mathrm{M})$ for $1 \mathrm{~h}$, and detected NF- $\kappa \mathrm{B}$ activation by EMSA in cell nuclear extracts (Figure 8). Furthermore, there was dose-dependent upregulation of IL-8 protein secretion by PTEC upon direct exposure to $\mathrm{H}_{2} \mathrm{O}_{2}(50,100$, 200 , or $400 \mu \mathrm{M}$ ) for $24 \mathrm{~h}$ (Figure $7 \mathrm{~b}$ ).

Endocytosis of albumin. Endocytosis of albumin by human PTECs was determined by incubating PTECs with FITC-HSA $(1.25-20 \mathrm{mg} / \mathrm{ml})$ for $0-4 \mathrm{~h}$. The

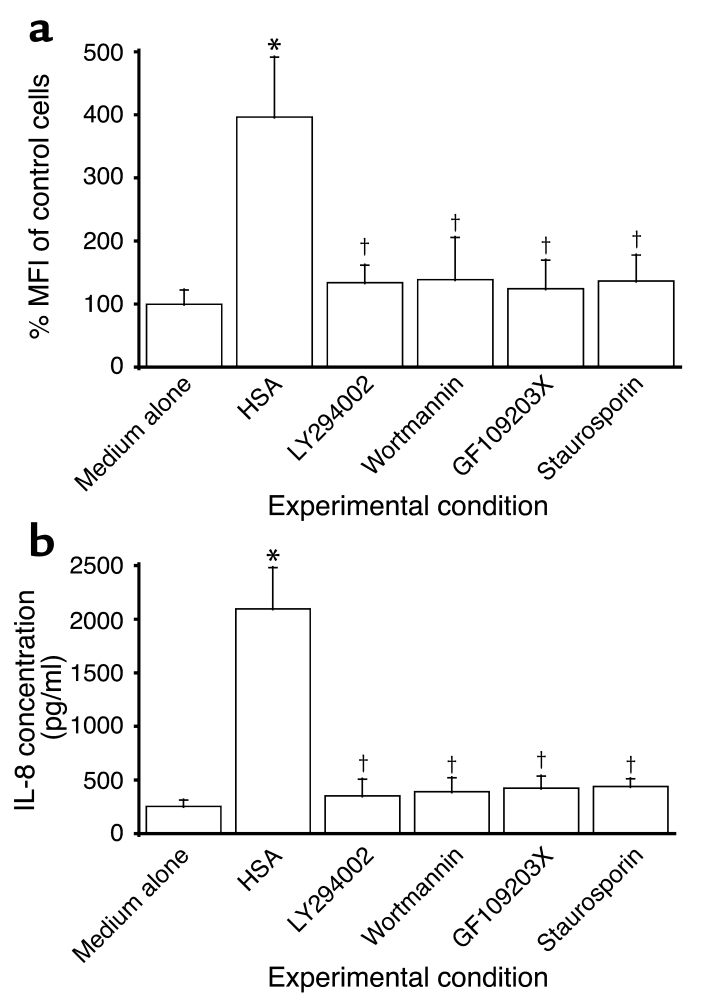




\section{Table 1}

Clinical data and renal IL-8-staining score by immunohistochemistry in nephrotic and non-nephrotic subjects

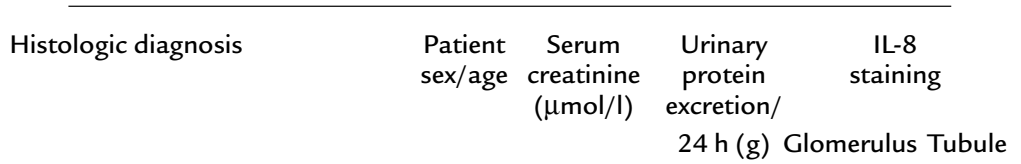

Nephrotic group $(n=18)$

Minimal change NS

Minimal change NS

Minimal change NS

Minimal change NS

Minimal change NS

Minimal change NS

Minimal change NS

Minimal change NS

Minimal change NS

Minimal change NS

Hypertensive nephrosclerosis

Hypertensive nephrosclerosis

Hypertensive nephrosclerosis

Hypertensive nephrosclerosis

Diabetic glomerulosclerosis

Diabetic glomerulosclerosis

Diabetic glomerulosclerosis

Diabetic glomerulosclerosis

Non-nephrotic group $(n=7)$

Minor glomerular abnormality

Minor glomerular abnormality

No abnormality

Minor glomerular abnormality

No abnormality (renal allograft) ${ }^{A}$

No abnormality (renal allograft) ${ }^{A}$

No abnormality (renal allograft) ${ }^{\mathrm{A}}$

\begin{tabular}{|c|c|c|c|}
\hline$F / 36$ & 81 & 22.0 & 10 \\
\hline $\mathrm{M} / 47$ & 89 & 15.0 & 0 \\
\hline $\mathrm{M} / 16$ & 80 & 6.0 & 10 \\
\hline $\mathrm{M} / 43$ & 100 & 8.0 & 0 \\
\hline$M / 62$ & 98 & 5.0 & 10 \\
\hline $\mathrm{M} / 27$ & 110 & 3.2 & 0 \\
\hline$F / 33$ & 69 & 4.0 & 0 \\
\hline $\mathrm{M} / 49$ & 70 & 3.4 & 0 \\
\hline$F / 19$ & 80 & 8.1 & 10 \\
\hline $\mathrm{M} / 53$ & 109 & 10.9 & 10 \\
\hline $\mathrm{M} / 45$ & 4430 & 3.0 & 2 \\
\hline$M / 66$ & 2500 & 2.0 & 1 \\
\hline M/81 & 1950 & 9.5 & 0 \\
\hline $\mathrm{M} / 38$ & 1320 & 2.6 & 1 \\
\hline$F / 58$ & 3600 & 11.0 & 0 \\
\hline $\mathrm{M} / 58$ & 1290 & 6.0 & 1 \\
\hline$F / 63$ & 1860 & 4.4 & 1 \\
\hline $\mathrm{M} / 73$ & 3500 & 7.3 & 0 \\
\hline M/49 & 990 & $<0.3$ & 0 \\
\hline$F / 69$ & 810 & 0.39 & 1 \\
\hline $\mathrm{M} / 29$ & 1040 & 0.07 & 0 \\
\hline $\mathrm{M} / 22$ & 830 & 0.9 & 0 \\
\hline$F / 36$ & 1400 & 0 & 1 \\
\hline $\mathrm{M} / 32$ & 1800 & 0 & 0 \\
\hline $\mathrm{M} / 42$ & 4400 & 0.8 & 0 \\
\hline
\end{tabular}

Aprotocol day 10 post-transplant allograft biopsy. NS, nephrotic syndrome. during incubation with HSA. The PI3K inhibitors completely abolished albumininduced oxidant generation (Figure 10a), NF-אB-DNA binding (Figure 8), and IL-8 production (Figure 10b).

Role of PKC. To further characterize the downstream intracellular events following endocytosis of albumin, we focused on PKC, because NF- $\kappa \mathrm{B}$ activation in protein-overloaded human PTECs is recently reported to be PKC dependent (33). The role of PKC activation was determined by preincubating and culturing PTECs with the PKC inhibitors GF109203X and staurosporin during albumin challenge. Oxidant generation (Figure 10a), NF-KBDNA binding (Figure 8), and the subsequent IL-8 production (Figure 10b) in PTECs were significantly suppressed by both PKC inhibitors.

Tissue localization of IL-8 expression in the nephrotic kidney. To localize the in vivo site of IL-8 synthesis in the nephrotic kidney, further studies were performed on renal biopsy tissues obtained from 18 subjects with heavy proteinuria due to nonproliferative glomerulopathies and from 7 subjects without significant proteinuria as control. The clinical data and histologic diagnoses in these 25 subjects are summarized in Table 1.

Immunohistochemistry. Paraffin sections of these human renal biopsy specimens were immunohistochemically stained using a specific $m A b$. The specificity of the $A b$ was confirmed by its application on cultured

intensity of FITC-HSA bound to PTECs was quantified by fluorescence spectrophotometry. As illustrated in Figure 9, there was time- and dose-dependent endocytosis of HSA by PTECs. The fluorescence signal peaked at $20 \mathrm{~min}$ of exposure and then fell progressively thereafter, reflecting the previous observation that endocytosed albumin is internalized and degraded by lysosomal hydrolysis (30).

Role of PI3K. It has been reported that PI3K regulates an early step in the receptor-mediated endocytosis (30, 31) of albumin by kidney PTECs (32). To investigate whether endocytosis of albumin is crucial in the cascade of intracellular events leading to IL-8 induction in albumin-overloaded PTECs, the PI3K inhibitors, LY294002 and wortmannin, were added $1 \mathrm{~h}$ before and

\section{Figure 11}

Specificity of anti-IL-8 Ab. Confluent, growth-arrested PTECs in medium alone (a) or exposed to $10 \mathrm{mg} / \mathrm{ml}$ albumin for $3 \mathrm{~h} \mathrm{(b)} \mathrm{were} \mathrm{incu-}$ bated with monoclonal anti-human IL-8 Ab $(10 \mu \mathrm{g} / \mathrm{ml})$ overnight. The bound murine anti-IL-8 Ab's were visualized with the DAKO Envision Plus System. (c) The Ab was preabsorbed with IL-8-immunizing peptides before incubation with PTECs exposed to albumin $(10 \mathrm{mg} / \mathrm{ml}$ for $3 \mathrm{~h}$ ), which attenuated the IL-8-staining signal. $\times 400$.
PTECs exposed to albumin or medium alone and by preabsorption of the Ab with IL-8-immunizing peptides before staining of albumin-treated cells (Figure 11). The intensity and distribution of IL-8 staining in human kidney tissues were reported by a renal histopathologist without previous knowledge of clinical data on an arbitrary scale of 0-3 (absent, mild, moderate, marked). The
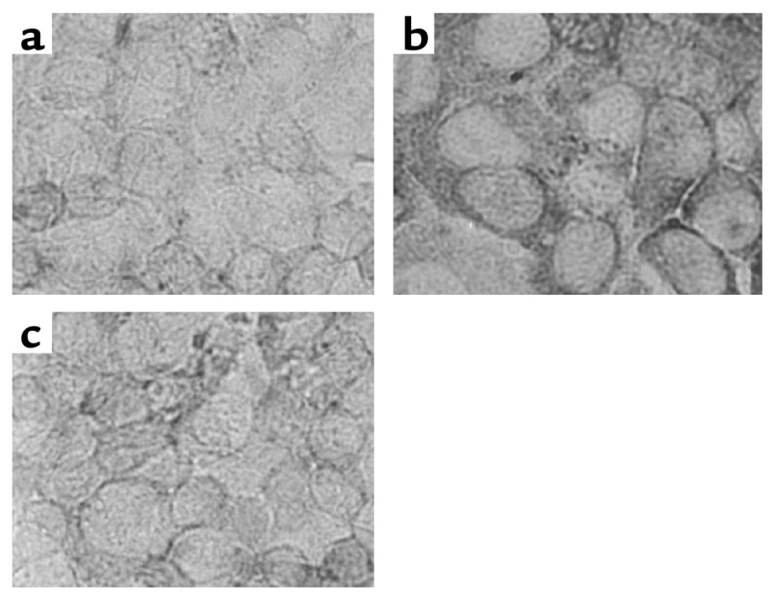

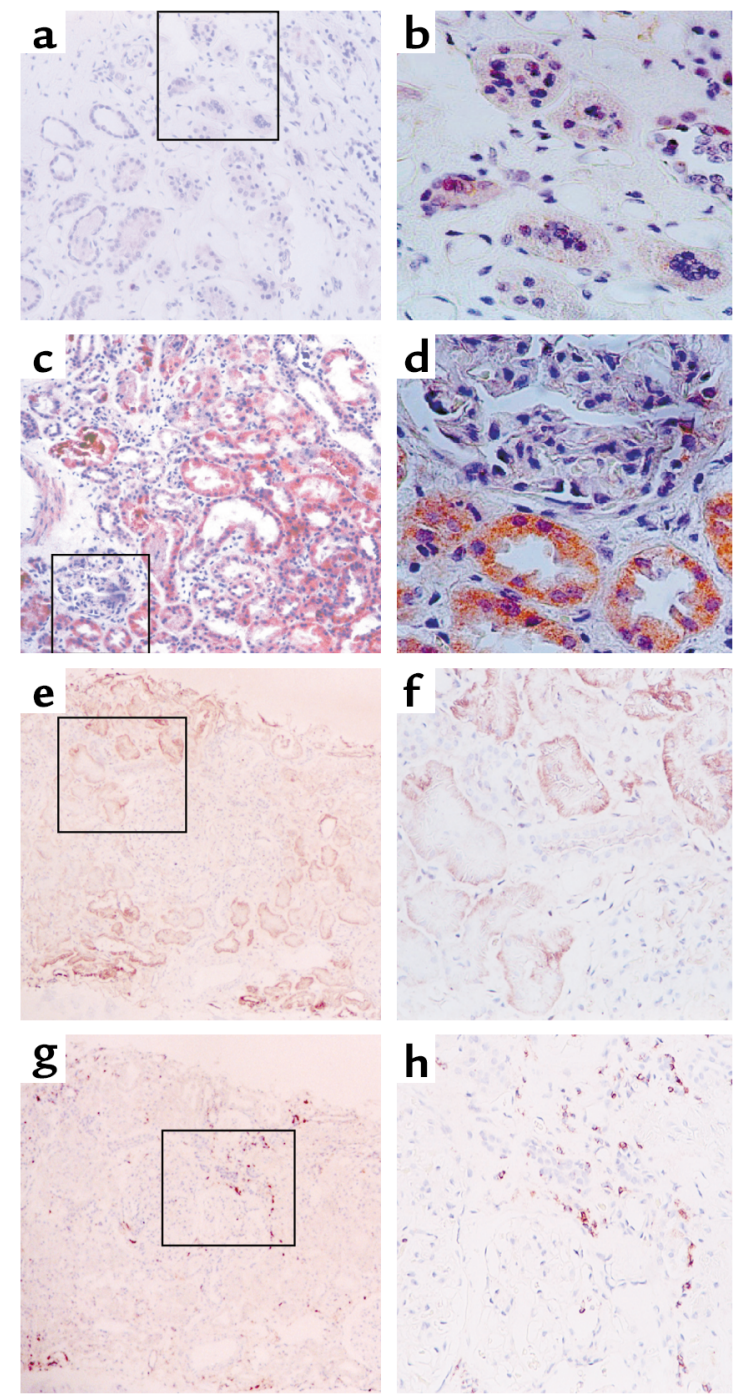

\section{Figure 12}

Immunohistochemical staining for IL-8 and infiltrating leukocytes. (a and $\mathbf{b}$ ). Representative experiment from a non-nephrotic control subject, showing background staining only. (c and $\mathbf{d}$ ) Representative staining from a nephrotic subject, demonstrating the predominance of tubular over glomerular staining for IL-8 protein. (e and f) IL-8 staining in tubules of a representative nephrotic subject followed a focal pattern of distribution. Staining of the section with anti-CD44 $\mathrm{mAb}$ ( $\mathbf{g}$ and $\mathbf{h}$ ) demonstrated infiltration by CD44-positive leukocytes of the interstitial space in the proximity of the IL-8-expressing tubules. $(\mathbf{a}, \mathbf{c}, \mathbf{e}, \mathbf{g}) \times 100 ;(\mathbf{b}, \mathbf{d}, \mathbf{f}, \mathbf{h}) \times 200$ of marked area in the corresponding left-hand panels, all counterstained with hematoxylin.

individual scores for glomerular and tubular staining for IL-8 were shown in Table 1 . In the nonnephrotic group, there was minimal glomerular and tubular staining for IL-8 (Figure 12, $a$ and b). In nephrotic subjects, there was positive tubular staining for IL-8 $(P=0.039$ versus nonnephrotic controls, Figure 13a) regardless of the underlying histopathologic diagnosis, while glomerular staining was relatively spared (Figure 12, $\mathrm{c}$ and $\mathrm{d}$ ). The distribution of IL-8 staining in the tubules of nephrotic kidneys followed a focal pattern and was associated with scattered influx of leukocytes in the interstitium (Figure
12 , $\mathrm{e}-\mathrm{h})$. Immunostaining for tubular IL-8 expression in the nephrotic group of subjects was weakly correlated with the magnitude of proteinuria $\left(r^{2}=0.332, b=0.116\right.$, [95\% confidence interval, 0.029-0.203], $P=0.012$, Figure $13 \mathrm{~b})$. No correlation was found between the staining score and age, gender, serum creatinine, or histopathologic diagnosis. Urinary IL-8 levels, assayed in seven subjects by ELISA, ranged from 14.1 to $62.5 \mathrm{pg} / \mathrm{ml}$ and did not correlate with the staining score, age, serum creatinine, or proteinuria (data not shown).

In situ bybridization. In situ hybridization for detection of local IL-8 mRNA expression was performed on kidney sections obtained from three nephrotic patients with histologic diagnosis of minimal-change nephrotic syndrome (urinary protein excretion was $21.7,6.6$, and $7.4 \mathrm{~g} / 24 \mathrm{~h}$, respectively) and three patients with membranous nephropathy (urinary protein excretion was $2.1,2.5$, and $3.2 \mathrm{~g} / 24 \mathrm{~h}$, respectively). In the normal human kidney, there was weak IL-8 mRNA signals observed in the glomeruli and no signal in the tubulointerstitium (Figure 14a). In minimal-change nephrotic syndrome and membranous nephropathy, in situ hybridization showed the presence of weak signals for IL- 8 mRNA within the glomerulus (Figure 14b), but markedly increased signals in renal tubular epithelial cells in the tubulointerstitium (Figure 14c). No signal was detected when the sections were hybridized with a sense probe (Figure 14d).

\section{Discussion}

Over the past decade, there has been intense interest in the possible link between excessive protein trafficking through the glomerulus and progressive renal tubulointerstitial inflammation leading to chronic renal failure. A hallmark of inflammation is the invasion into injured tissue by activated leukocytes. This step is critically dependent on the rapid expression of chemokines (34). In the nephrotic state, the glomerular ultrafiltrate contains plasma proteins. Data are already available to show that overexposure to filtered proteins upregulates tubular expression of vasoactive and proinflammatory mediators such as ET-1 (35), MCP-1 (9), RANTES (10), and more recently from our laboratory, C3 (36) and macrophage migration inhibitory factor (37). IL-8 is a key proinflammatory chemokine responsible for recruiting and activating neutrophils, $\mathrm{T}$ cells, and monocytes to sites of inflammation (11,12, 38-40). Here we showed, we believe for the first time that albumin induces IL-8 in PTECs at both the transcriptional and translational levels. Although such data could not be directly extrapolated to the in vivo setting, the rapid and intense induction of IL-8 strongly suggests a case for albumin-induced, tubule-secreted IL-8 in orchestrating the influx of inflammatory cells into the kidney. This contention is further supported by indirect evidence from animal studies, where the administration of a neutralizing anti-IL-8 $\mathrm{Ab}$ prevented albuminuria and glomerular infiltration of neutrophils (41).

Trypsin digestion or thermal denaturation of albumin effectively abrogated IL-8 induction in PTECs. 

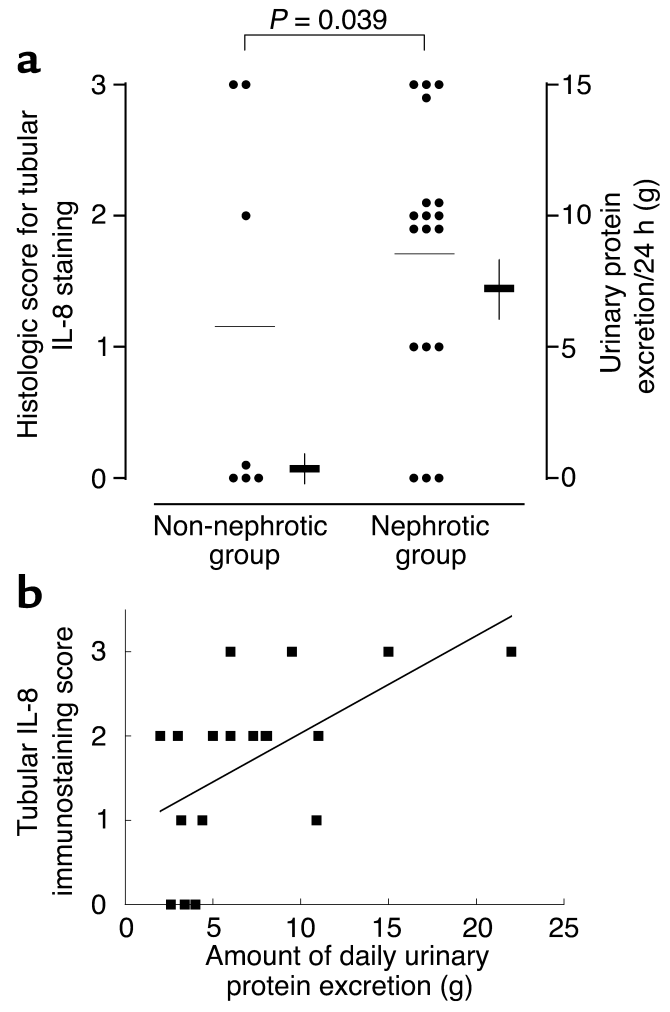

This, together with the uniform results using different brands of HSA, alleviates the concern that the observed effect might be mediated by a nonproteinaceous compound attached to albumin in the manufacturing process. The relatively high dose of albumin used in our short-term culture system may be necessary to simulate more prolonged exposure, as occurs in vivo. Other researchers investigating the impact of albumin on PTECs have employed a similar range of protein concentration $(9,10,35,36,42-45)$.

The effect of albumin is not unique to renal epithelial cells. Indeed, albumin also stimulated IL-8 expression in HT-29 and A549 cell lines. The pathophysiologic significance of such findings is limited, however. Apart from albumin, transferrin and IgG are other serum proteins filtered in patients with heavy proteinuria. Congruent with our previous finding (37), transferrin is also capable of inducing tubular IL-8 expression, albeit to a much lesser extent than albumin. Thus, as least two components of nephrotic urine stimulate tubular IL-8 expression.

The induction of tubular IL-8 expression upon protein challenge is not limited to cells in culture. Using in

\section{Figure 14}

Detection of IL-8 mRNA by in situ hybridization. Normal kidney section displayed a paucity of IL-8 mRNA signal in the glomerulus and absent signal in the tubulointerstitium (a). $\times 200$. In the nephrotic kidney, represented by a kidney section from a subject with minimal change nephrotic syndrome here, the signal for IL-8 mRNA was very weak in the glomeruli, but was markedly more intense in the tubulointerstitium (b) (×200) and strongly expressed in tubular epithelial cells $($ c). $\times 400$. Negative control was performed using a sense probe, with no signal detected $(\mathbf{d}) . \times 200$.

\section{Figure 13}

Histologic score for IL-8 immunostaining in renal tubules. (a) Scoring in non-nephrotic versus nephrotic subjects. Immunohistochemical staining for tubular IL-8 antigen was performed on renal biopsy specimens obtained from 25 patients with nephrotic range or minimal proteinuria and graded in an observer-blinded manner on an arbitrary scale of $0-3$ (see text for scoring criteria). Circles and horizontal lines are individual scores of each patient and mean scores in each group, respectively. Horizontal bars and vertical lines are means \pm SE of daily urinary protein excretion in each group. (b) Correlation between the magnitude of proteinuria and staining score for IL-8 in renal tubules of 18 nephrotic subjects by linear regression $\left(r^{2}=0.332\right.$, $b=0.116$ [95\% confidence interval, 0.029-0.203], $P=0.012$ ).

situ hybridization techniques, the anatomic site of IL-8 mRNA expression is localized in vivo to the proximal tubular epithelia. There were intense signals for IL-8 mRNA in the renal tubules of nephrotic subjects, while non-nephrotic subjects showed absent tubular IL-8 mRNA signal. Furthermore, using immunohistochemistry to confirm and localize IL-8 protein synthesis, we demonstrated that kidney biopsies from nephrotic subjects displayed stronger IL-8 staining than those from minimally proteinuric control subjects, suggesting the importance of proteinuria in this context. On the other hand, the correlation between the severity of proteinuria and the intensity of tubular IL-8 signals, though reaching statistical significance, was weak. Such correlation requires better control of factors influencing tubular IL-8 expression in a larger cohort.

Since the major cellular component of the inflammatory reaction that follows protein overabsorption occurs in the interstitial space, we characterized the polarity of IL-8 secretion by PTECs. In the quiescent state, small amounts of IL-8 are secreted into both apical and basolateral aspects. This is understandable because IL-8 synthesis is low or undetectable in noninflamed tissue (46). Upon challenge with albumin apically, IL-8 was secreted predominantly into the basolateral medium. The demonstration of leukocytes infiltrating the interstitium in the proximity of IL-8-expressing renal tubules of nephrotic subjects suggests that such directional secretion of IL-8 may indeed occur in vivo. The effect of basolateral exposure was much weaker, reflecting the predominantly apical location of the receptors for albumin $(30,31)$. Collectively, we postulate that IL-8 generated in response to

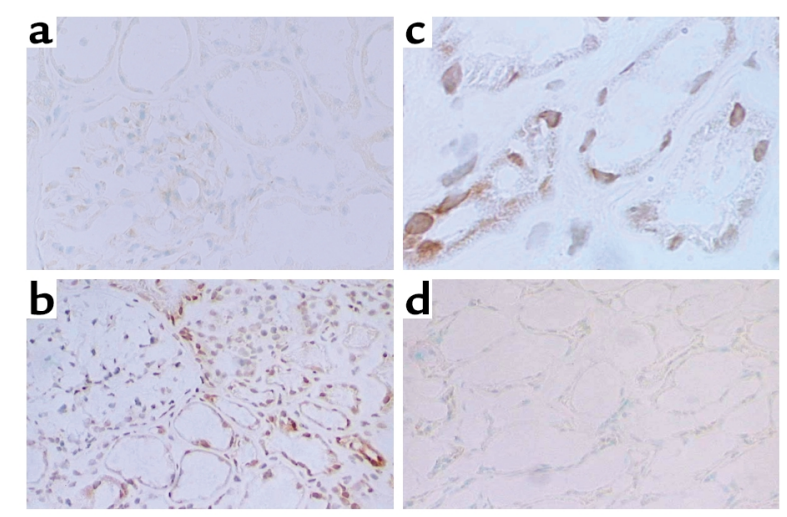


protein overload may accumulate in the interstitial space, which is consistent with its chemotactic function.

The signal transduction pathways governing the transcription of IL-8 expression in PTECs are not well understood. Because NF- $\mathrm{\kappa B}$ controls the transcription of a number of proinflammatory genes (47), including those involved in the pathogenesis of glomerular and tubular diseases, we examined whether IL-8 synthesis by protein-overloaded PTECs was NF- $\kappa$ B dependent. Our data demonstrate that albumin-induced upregulation of tubular IL-8 involves nuclear translocation of $\mathrm{NF}-\kappa \mathrm{B}$. Five pieces of evidence support this contention: (a) albumin activated the p50 and p65 subunits of NF- $\kappa \mathrm{B}$ dose dependently; (b) EMSA demonstrated nuclear translocation of NF- $\kappa B$, which was blocked by PDTC, or SN50, but not its mutated peptide; (c) inhibition of NF- $\mathrm{KB}$ with PDTC or SN50 attenuated albumin-induced IL-8 production; (d) previous studies showed that a sequence spanning the nucleotides -1 to -133 within the 5 '-flanking region of the human IL-8 gene contained binding sites for $\kappa \mathrm{B}$ proteins $(48,49)$; and (e) NF- $\kappa \mathrm{B}$ is activated in the renal tubules of proteinuric subjects (50). Our results are in agreement with previous reports that $\mathrm{NF}-\kappa \mathrm{B}$ was activated by BSA in a pig PTEC line, LLC-PK 1 (10), and in rat PTECs (42). Our findings are unique in that human serum albumin was used on human PTECs in primary culture.

The intracellular signaling mechanism that underlies albumin-induced NF- $\kappa \mathrm{B}$ activation in PTECs remains to be elucidated. The ability of the antioxidant, PDTC, to block albumin-induced NF- $\mathrm{KB}$ activation and IL-8 synthesis, coupled with previous observation that ROS activated NF- $\mathrm{KB}$ in endothelial cells (51) and induced IL-8 expression in other cell systems (52), suggested oxygen radicals are likely to be second messengers in mediating $\mathrm{NF}-\kappa \mathrm{B}$ activation. Here we showed that exogenous $\mathrm{H}_{2} \mathrm{O}_{2}$ stimulated NF- $\kappa \mathrm{B}-\mathrm{DNA}$ binding and IL-8 secretion in PTECs. In addition, the ROS content of PTECs was upregulated dose dependently by albumin. These findings strongly suggest a role of ROS in the intracellular signaling process, as further supported by the recent observation of $\mathrm{H}_{2} \mathrm{O}_{2}$-dependent $\mathrm{NF}-\kappa \mathrm{B}$ activation in HK-2 cells (33).

To further dissect the upstream signals leading to ROS generation, we examined the role of PKC, a family of ubiquitous serine/threonine kinases. When activated, PKC is known to translocate from cytoplasm to cell membrane to mediate ROS production and NF- $\kappa B$ activation in other cell systems (53). Here we demonstrated that the PKC inhibitors, GF109203X and staurosporin, markedly suppressed ROS generation and NF- $\kappa B-D N A$ binding in albumin-stimulated PTECs. Furthermore, PKC inhibition resulted in complete abrogation of albumin-induced IL-8 production. These findings provide evidence that PKC serves as an upstream mediator of ROS generation and the subsequent NF- $\mathrm{KB}$ activation.

How albumin overload induces PKC and the ensuing downstream events that culminate in IL- 8 induction remains to be addressed. Here we showed that albumin is endocytosed by PTECs in a time- and dose-dependent manner, which is in agreement with previous reports that albumin uptake by PTECs is mediated through the endocytic receptors, megalin (31) and cubilin (30). An important question is whether the endocytosis of albumin is crucial. PI3K belongs to a family of phosphoinositide 3-kinases that regulate endocytosis and other vesicular trafficking events $(54,55)$. Here we documented that blockade of albumin endocytosis using the PI3K inhibitors, LY294002 and wortmannin, completely abolished albumin-induced oxidant generation, NF- $\mathrm{BB}-\mathrm{DNA}$ binding, and IL-8 production, supporting a cell biological link between albumin endocytosis and the ensuing intracellular events. Taken together, it is tempting to speculate that receptor-mediated endocytosis of albumin by PTECs activates PKC that is essential for ROS generation. Finally, ROS function as the critical messenger for $\mathrm{NF}-\kappa \mathrm{B}$ activation and the consequent transcription of IL-8. Endocytosed albumin is then concentrated in late endosomes and lysosomes for degradation, while the receptors are recycled to the apical membrane (30).

Apart from stimulating IL-8, albumin has been shown to induce two other NF- $\mathrm{BB}$-dependent proinflammatory genes in PTECs, namely MCP-1 (9) and RANTES (10). It is therefore logical to assume that overloading PTECs with albumin leads to a common pathway of activating NF- $\kappa \mathrm{B}$-dependent genes whose chemotactic protein products act in concert to orchestrate a complex cascade of events that translate the original glomerulopathy into cellular signals of tubulointerstitial inflammation. These signals might then be relayed back to the glomerulus by tubuloglomerular cross-talk mechanisms to perpetuate further glomerular damage (37).

In summary, this study is the first, to our knowledge, to show that albumin stimulates tubular IL-8 expression, which is dependent on the endocytosis of albumin that triggers a cascade of intracellular signals from PKC-dependent activation of ROS generation to nuclear translocation of NF- $\mathrm{BB}$. Currently, therapeutic interventions are aimed primarily at reducing glomerular protein ultrafiltration and controlling systemic hypertension. It is conceivable that future therapeutic strategies may be targeted at the pathobiologic processes that lie further downstream, namely the interaction of filtered proteins with tubular epithelial cells and their activation. Understanding the molecular basis of this interaction is likely to yield novel insight into the pathology of inflammation and may ultimately result in the development of new anti-inflammatory drugs.

\section{Acknowledgments}

This study was supported by the University Department of Medicine Research Grant (HKUDM 2000/2001), University Research Committee Seeding Grant (2001/2002), Research Grant Council (HKU7263/01M), and the Mr. and Mrs. Liu Lit Ching Research Fund. L.Y.Y. Chan was supported by the Fresenius Medical Care. 
1. Benigni, A., Zoja, C., and Remuzzi, G. 1995. The renal toxicity of sustained glomerular protein traffic. Lab. Invest. 73:461-468.

2. Jerums, G., et al. 1997. Why is proteinuria such an important risk factor for progression in clinical trials? Kidney Int. 52(Suppl.):S87-S92.

3. Klahr, S., et al. 1994. The effects of dietary protein restriction and bloodpressure control on the progression of chronic renal disease. Modification of Diet in Renal Disease Study Group. N. Engl. J. Med. 330:877-884.

4. Eddy, A.A. 1989. Interstitial nephritis induced by protein-overload proteinuria. Am. J. Pathol. 135:719-733.

5. Eddy, A.A., McCulloch, L., Liu, E., and Adams, J. 1991. A relationship between proteinuria and acute tubulointerstitial disease in rats with experimental nephrotic syndrome. Am. J. Pathol. 138:1111-1123.

6. Hirschberg, R. 1996. Bioactivity of glomerular ultrafiltrate during heavy proteinuria may contribute to renal tubulo-interstitial lesions: evidence for a role for insulin-like growth factor I. J. Clin. Invest. 98:116-124.

7. Remuzzi, G., Ruggenenti, P., and Benigni, A. 1997. Understanding the nature of renal disease progression. Kidney Int. 51:2-15.

8. Van Goor, H., et al. 1994. Macrophages and renal disease. Lab. Invest. 71:456-464.

9. Wang, Y., et al. 1997. Induction of monocyte chemoattractant protein-1 in proximal tubule cells by urinary protein. J. Am. Soc. Nephrol. 8:1537-1545.

10. Zoja, C., et al. 1998. Protein overload stimulates RANTES production by proximal tubular cells depending on NF- $\mathrm{KB}$ activation. Kidney Int. 53:1608-1615.

11. Larsen, C.G., Anderson, A.O., Appella, E., Oppenheim, J.J., and Matsushima, K. 1989. The neutrophil-activating protein (NAP-1) is also chemotactic for T lymphocytes. Science. 243:1464-1466.

12. Schmouder, R.L., Strieter, R.M., Wiggins, R.C., Chensue, S.W., and Kunkel, S.L. 1992. In vitro and in vivo interleukin-8 production in human renal cortical epithelia. Kidney Int. 41:191-198.

13. Gerritsma, J.S., et al. 1996. Regulation and production of IL-8 by human proximal tubular epithelial cells in vitro. Clin. Exp. Immunol. 103:289-294.

14. Yokoyama, H., et al. 1998. Urinary levels of chemokines (MCAF/MCP-1, IL-8) reflect distinct disease activities and phases of human IgA nephropathy. J. Leukoc. Biol. 63:493-499.

15. Wada, T., et al. 1994. Detection of urinary interleukin-8 in glomerular diseases. Kidney Int. 46:455-460.

16. Detrisac, C.J., Sens, M.A., Garvin, A.J., Spicer, S.S., and Sens, D.A. 1984. Tissue culture of human kidney epithelial cells of proximal tubule origin. Kidney Int. 25:383-390.

17. Phillips, A.O., Steadman, R., Topley, N., and Williams, J.D. 1995. Elevated D-glucose concentrations modulate TGF-beta 1 synthesis by human cultured renal proximal tubular cells. The permissive role of plateletderived growth factor. Am. J. Pathol. 147:362-374.

18. Chomczynski, P., and Sacchi, N. 1987. Single-step method of RNA isolation by acid guanidinium thiocyanate-phenol-chloroform extraction. Anal. Biochem. 162:156-159.

19. Tang, S., et al. 2001. In vitro studies of aquaporins 1 and 3 expression in cultured human proximal tubular cells: upregulation by transferrin but not albumin. Am. J. Kidney Dis. 38:317-330.

20. Neubauer, A., Neubauer, B., and Liu, E. 1990. Polymerase chain reaction based assay to detect allelic loss in human DNA: loss of beta-interferon gene in chronic myelogenous leukemia. Nucleic Acids Res. 18:993-998.

21. Leung, J.C., Tsang, A.W., Chan, D.T., and Lai, K.N. 2000. Absence of CD89, polymeric immunoglobulin receptor, and asialoglycoprotein receptor on human mesangial cells. J. Am. Soc. Nephrol. 11:241-249.

22. Farruggia, B., and Pico, G.A. 1999. Thermodynamic features of the chemical and thermal denaturations of human serum albumin. Int. J. Biol. Macromol. 26:317-323

23. Foulds, S. 1997. Novel flow cytometric method for quantifying nuclear binding of the transcription factor NF- $\mathrm{KB}$ in unseparated human monocytes and polymorphonuclear cells. Cytometry. 29:182-186.

24. Schreck, R., Meier, B., Mannel, D.N., Droge, W., and Baeuerle, P.A. 1992 Dithiocarbamates as potent inhibitors of NF- $\mathrm{KB}$ activation in intact cells. J. Exp. Med. 175:1181-1194.

25. Lin, Y.Z., Yao, S.Y., Veach, R.A., Torgerson, T.R., and Hawiger, J. 1995. Inhibition of nuclear translocation of transcription factor NF- $\kappa$ B by a synthetic peptide containing a cell membrane-permeable motif and nuclear localization sequence. J. Biol. Chem. 270:14255-14258.

26. Mukaida, N., Shiroo, M., and Matsushima, K. 1989. Genomic structure of the human monocyte-derived neutrophil chemotactic factor IL-8. J. Immunol. 143:1366-1371.

27. Abe, K., et al. 2001. Enhanced expression of complement C5a receptor mRNA in human diseased kidney assessed by in situ hybridization. Kidney Int. 60:137-146.

28. Miyazaki, M., et al. 1996. Intraglomerular C3 synthesis in human kidney detected by in situ hybridization. J. Am. Soc. Nephrol. 7:2428-2433.
29. Koji, T., and Brenner, R.M. 1993. Localization of estrogen receptor messenger ribonucleic acid in rhesus monkey uterus by nonradioactive in situ hybridization with digoxigenin-labeled oligodeoxynucleotides. Endocrinology. 132:382-392.

30. Birn, H., et al. 2000. Cubilin is an albumin binding protein important for renal tubular albumin reabsorption. J. Clin. Invest. 105:1353-1361.

31. Cui, S., Verroust, P.J., Moestrup, S.K., and Christensen, E.I. 1996. Megalin/gp330 mediates uptake of albumin in renal proximal tubule. Am.J. Physiol. 271:F900-F907.

32. Brunskill, N.J., Stuart, J., Tobin, A.B., Walls, J., and Nahorski, S. 1998. Receptor-mediated endocytosis of albumin by kidney proximal tubule cells is regulated by phosphatidylinositide 3-kinase. J. Clin. Invest. 101:2140-2150.

33. Morigi, M., et al. 2002. Protein overload-induced NF- $\kappa B$ activation in proximal tubular cells requires $\mathrm{H}_{2} \mathrm{O}_{2}$ through a PKC-dependent pathway. J. Am. Soc. Nephrol. 13:1179-1189.

34. Baggiolini, M. 1998. Chemokines and leukocyte traffic. Nature. 392:565-568.

35. Zoja, C., et al. 1995. Proximal tubular cell synthesis and secretion of endothelin-1 on challenge with albumin and other proteins. Am. J. Kidney Dis. 26:934-941.

36. Tang, S., Sheerin, N.S., Zhou, W., Brown, Z., and Sacks, S.H. 1999. Apical proteins stimulate complement synthesis by cultured human proximal tubular epithelial cells. J. Am. Soc. Nephrol. 10:69-76.

37. Tang, S., et al. 2002. Transferrin up-regulates chemokine synthesis by human proximal tubular epithelial cells: Implication on mechanism of tubuloglomerular communication in glomerulopathic proteinuria. Kidney Int. 61:1655-1665.

38. Yoshimura, T., Matsushima, K., Oppenheim, J.J., and Leonard, E.J. 1987. Neutrophil chemotactic factor produced by lipopolysaccharide (LPS)stimulated human blood mononuclear leukocytes: partial characterization and separation from interleukin 1 (IL 1). J. Immunol. 139:788-793.

39. Strieter, R.M., et al. 1994. The immunopathology of chemotactic cytokines: the role of interleukin- 8 and monocyte chemoattractant protein-1. J. Lab. Clin. Med. 123:183-197.

40. Zernecke, A., et al. 2001. Combinatorial model of chemokine involvement in glomerular monocyte recruitment: role of CXC chemokine receptor 2 in infiltration during nephrotoxic nephritis. J. Immunol. 166:5755-5762

41. Wada, T., et al. 1994. Prevention of proteinuria by the administration of anti-interleukin 8 antibody in experimental acute immune complexinduced glomerulonephritis. J. Exp. Med. 180:1135-1140.

42. Wang, Y., Rangan, G.K., Tay, Y.C., and Harris, D.C. 1999. Induction of monocyte chemoattractant protein-1 by albumin is mediated by NF- $\kappa \mathrm{B}$ in proximal tubule cells. J. Am. Soc. Nephrol. 10:1204-1213.

43. Chen, L., Boadle, R.A., and Harris, D.C. 1998. Toxicity of holotransferrin but not albumin in proximal tubule cells in primary culture. J. Am. Soc. Nephrol. 9:77-84.

44. Burton, C.J., et al. 2001. Turnover of human tubular cells exposed to proteins in vivo and in vitro. Kidney Int. 59:507-514.

45. Burton, C.J., Combe, C., Walls, J., and Harris, K.P. 1996. Fibronectin production by human tubular cells: the effect of apical protein. Kidney Int. 50:760-767.

46. Baggiolini, M., and Clark-Lewis, I. 1992. Interleukin-8, a chemotactic and inflammatory cytokine. FEBS Lett. 307:97-101.

47. Barnes, P.J., and Karin, M. 1997. Nuclear factor-kappa B: a pivotal transcription factor in chronic inflammatory diseases. N. Engl. J. Med. 336:1066-1071.

48. Mukaida, N., Okamoto, S., Ishikawa, Y., and Matsushima, K. 1994. Molecular mechanism of interleukin-8 gene expression. J. Leukoc. Biol. 56:554-558.

49. Nourbakhsh, M., et al. 2001. The NF- $\kappa B$ repressing factor is involved in basal repression and interleukin (IL)-1-induced activation of IL-8 transcription by binding to a conserved NF- $\mathrm{KB}$-flanking sequence element. J. Biol. Chem. 276:4501-4508.

50. Mezzano, S.A., et al. 2001. Tubular NF-אB and AP-1 activation in human proteinuric renal disease. Kidney Int. 60:1366-1377.

51. Rahman, A., Kefer, J., Bando, M., Niles, W.D., and Malik, A.B. 1998. E-selectin expression in human endothelial cells by TNF-alpha-induced oxidant generation and NF-KB activation. Am. J. Physiol. 275:L533-L544.

52. DeForge, L.E., et al. 1993. Regulation of interleukin 8 gene expression by oxidant stress. J. Biol. Chem. 268:25568-25576.

53. Inoguchi, T., et al. 2000. High glucose level and free fatty acid stimulate reactive oxygen species production through protein kinase $\mathrm{C}$-dependent activation of $\mathrm{NAD}(\mathrm{P}) \mathrm{H}$ oxidase in cultured vascular cells. Diabetes. 49:1939-1945.

54. Liscovitch, M., and Cantley, L.C. 1995. Signal transduction and membrane traffic: the PITP/phosphoinositide connection. Cell. 81:659-662.

55. De Camilli, P., Emr, S.D., McPherson, P.S., and Novick, P. 1996. Phosphoinositides as regulators in membrane traffic. Science. 271:1533-1539. 